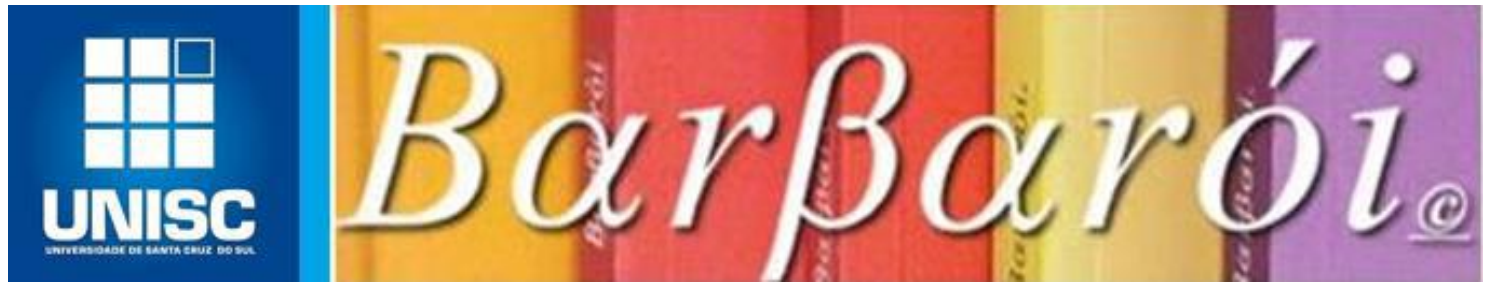

\title{
SOCIEDADE, EDUCAÇÃO E DESIGUALDADE: UM PANORAMA SOBRE TEORIAS E PESQUISAS
}

\author{
DOI: http://dx.doi.org/10.17058/barbaroi.v1i53.13698

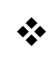

Bernardo Caprara

Universidade Federal da Fronteira Sul

$*$

\section{Resumo}

$\mathrm{O}$ artigo discute as relações entre sociedade, educação e desigualdades sociais. O objetivo do texto é mapear as contribuições sobre a temática, com o foco em diferentes abordagens, partindo do funcionalismo, passando pelas teorias da reprodução, pela estratificação educacional e a Sociologia da escola, até chegar à diversidade de análises proposta a partir da década de 1980. Resgata as contribuições dessas teorias e pesquisas, de maneira introdutória, considerando seus avanços e recuos, seus alcances e limitações. Assim, organiza um panorama em forma de síntese acerca de uma das relações mais frequentes nos debates sobre os fenômenos educacionais da modernidade.

Palavras-chave: Sociedade; Educação; Desigualdades.

\section{Apresentação}

A educação é um tema tradicional para as Ciências Humanas. É possível pensar os fenômenos educacionais a partir de diversos prismas, linhagens e autores. No século passado, as relações entre as sociedades modernas, as instituições responsáveis pela educação formal e as desigualdades sociais estiveram no centro de diferentes teorizações fomentadas por evidências empíricas.

O objetivo do artigo é construir um panorama das abordagens realizadas pela Sociologia e suas adjacências acerca das relações entre sociedade, educação e desigualdade, atentando tanto para as suas formulações teóricas, quanto para seus achados empíricos. Dessa forma, pretende-se apresentar e discutir, de maneira introdutória, um conjunto de contribuições fundamentais, produzindo um mapeamento sintético sobre a temática. 
O texto se divide em quatro partes: primeiro, apresenta a visão funcionalista sobre a educação e as lacunas deixadas por ela, que abriram espaço para novos estudos, nos quais a dimensão das desigualdades emerge com força; depois, discute as perspectivas "reprodutivistas", calcadas em desenvolver o argumento de que a educação formal colabora para a reprodução das desigualdades sociais; na sequência, é debatida uma gama de trabalhos que podem ser agrupados nos termos de "desigualdades de oportunidades educacionais" ou "estratificação educacional"; finalmente, é sugerida a necessidade de ampliar os esquemas interpretativos, seguindo os movimentos dos trabalhos desenvolvidos desde a década de 1980, cuja ênfase se volta para as dinâmicas internas à escolarização e para um detalhamento maior das mediações entre sociedade, educação e desigualdades.

\section{Funcionalismo e educação}

Sob a égide do funcionalismo, é possível pensar a educação como um instrumento para a mobilidade social. Para a "teoria da modernização" (PARSONS, 1970; TREIMAN, 1970), a educação formal teria o caráter de instituição equalizadora das oportunidades sociais. A escola, ao cumprir a sua função nas sociedades modernas, seria capaz de ultrapassar as estruturas mais fortalecidas de difusão e processamento direto das posições sociais estabelecidas entre as diferentes gerações.

Segundo Parsons (1970), as sociedades se estruturam embasadas em quatro sistemas: o sistema cultural, o social, o sistema da personalidade e o sistema do organismo, esse último relativo aos aspectos comportamentais. O sistema cultural lida com o significado. A ação humana somente ocorre porque existem sistemas simbólicos relativamente estáveis, com valores compartilhados capazes de definir avaliações morais e adjetivações. São valores adquiridos na socialização e que fazem da escolarização uma força de integração social, e não de conflitos.

As análises funcionalistas, contudo, deixaram muitas lacunas. O trabalho de pesquisa longitudinal efetuado pelo Institut National D’Êtudes Démographiques (INED), entre 1962 e 1972, na França, é considerado um suporte informativo pioneiro sobre a orientação e seleção escolar. Durante uma dezena de anos, 17.461 estudantes foram analisados com base em diversos fatores, como idade, sexo, origem social, demandas familiares e pareceres dos professores. Forquin (1995), falando sobre a realidade francesa, descreve que os êxitos, na avaliação dos educadores, e a idade em que os alunos atingiam, na $4^{\mathrm{a}}$ série, retratavam dois fundamentos para a continuidade nas trajetórias escolares. Também o ambiente geográfico marcava um importante aspecto de permanência, havendo diferenças entre as zonas rurais e Barbarói, Santa Cruz do Sul, n.53, p.<89-116>, jan./jun. 2019 
urbanas. O meio social igualmente adquiria relevância, sobretudo porque os filhos de executivos das classes abastadas tinham duas vezes mais chances de passar para a quinta série do que os filhos de operários. Uma das conclusões válidas da pesquisa do INED reforça o impacto das desigualdades de acesso e o agravo que ocorre nessas desigualdades no decorrer dos percursos educacionais.

Os pareceres dos professores indicavam que, na etapa da quarta série, os alunos percebidos como "bons" ou "excelentes" eram duas vezes mais encontrados entre os filhos dos executivos, na comparação com os operários. "Em complemento, impõe-se uma outra explicação: a partir de sucesso escolar igual, a demanda de escolarização difere bastante segundo os meios sociais" (FORQUIN, 1995, p. 25). Os educadores, por sua vez, acabavam por considerar, de forma consciente ou não, nas suas avaliações, as "identidades sociais" dos educandos. Isso se dava separadamente dos resultados obtidos por eles, na medida em que $78 \%$ dos alunos oriundos das famílias de executivos se beneficiaram com pareceres favoráveis, mesmo se tratando de notas medianas. Quando estavam em jogo os filhos dos operários, somente $30 \%$ receberam tal qualificação.

As probabilidades reais de transformação social através dos sistemas educacionais passaram a despertar muitas dúvidas. Nos Estados Unidos e na Inglaterra, foram elaborados documentos a pedido dos governos, originados de pesquisas empíricas. O Relatório Coleman (1966) e o Relatório Plowden (1967), respectivamente, demonstravam que não bastava investir na formulação de políticas que organizassem oportunidades iguais no sistema escolar, porque os resultados das camadas desprivilegiadas se conservavam inferiores aos dos grupos dominantes. Como consequência, "[...] os governos adoptam uma nova perspectiva, que consiste num deslocamento da lógica de igualdade para uma lógica de equidade: a distribuição de recursos deve ser diferenciada em função das necessidades também diferenciadas" (SEABRA, 2009, p. 77).

Forquin (1995) relata o teor do Relatório Plowden e nota a influência dos componentes familiares, sociais e escolares no desempenho dos jovens na escolarização. A partir de um teste de entendimento de leitura textual, havia indícios de que as práticas dos pais, atinentes à vida escolar dos filhos, detinham uma importância bastante mais acentuada do que as condições materiais com as quais a família vivia. Desenvolve-se a noção de que o alcance de bons ou maus resultados escolares estava interligado aos quesitos sociais e familiares, enquanto apareciam em segundo plano as dimensões pedagógicas ou próprias do funcionamento da escola. 


\section{Reprodução das desigualdades via escolarização}

Pouco depois da metade do século XX, solidificaram-se as análises sociológicas que não adornavam a educação formal com tantas expectativas transformadoras ou democráticas quanto propunham as perspectivas liberais e funcionalistas. Ocorre que floresceu todo um campo de estudos que passou a arguir a educação formal nas suas bases, refletindo sobre o papel que a escolarização poderia ter como instituição central para a reprodução das desigualdades nas sociedades modernas.

Uma das formas críticas de ver a escola aponta para a linguagem das crianças cujos desempenhos não são satisfatórios nas instituições educacionais como motivação das suas mazelas acadêmicas. O empenho de Basil Bernstein (1981) se voltou para analisar as falas de crianças originárias de setores operários e de crianças provenientes de classes abastadas. Bernstein discorreu sobre o que determinou como a "teoria dos dois códigos". Existiriam dois tipos de linguagem, duas modalidades de uso da linguagem: "o código restrito" e o "código elaborado". Ambos os códigos orientam as maneiras de se relacionar com o mundo.

Por "código restrito" é possível entender uma linguagem comum, entrelaçada ao contexto, geralmente falada pelos jovens das classes trabalhadoras, difícil de ser desassociada da vida cotidiana. O "código elaborado" representaria uma linguagem formal, compartilhada e utilizada desde sempre pelos jovens das classes abastadas. No conjunto dos "códigos elaborados", há menos dependência das situações reais, de "imagens" da vida cotidiana, pois se trata de um arcabouço linguístico universalizado. Essa distância entre os dois códigos encerraria a distância social entre classes e, no âmbito escolar, sustentaria a dificuldade de obtenção de "sucesso" por parte dos jovens portadores do "código restrito".

Já as abordagens neomarxistas propunham que o papel da escolarização estaria voltado para a reprodução das relações sociais de produção. A função da escola seria a preparação da força de trabalho pacata e bem afeiçoada à hierarquia dos mecanismos econômicos no capitalismo. As diferenças nos desempenhos escolares espelhavam as desigualdades do mundo do trabalho e, através da instituição escolar, era recomposta a ideologia das classes dominantes, fazendo com que os jovens trabalhadores se "adaptassem" desde cedo aos ditames das modernas sociedades capitalistas (ALTHUSSER, 1980; BAUDELOT \& ESTABLET, 1975; BOWLES \& GINTIS, 1974).

Althusser (1980) caracteriza as diferentes instituições da modernidade, como a escola, a política, a família e a igreja, por exemplo, dentro do que chamou de "Aparelhos Ideológicos do Estado". Delas decorreriam duas funções: a primeira envolveria a propagação da ideologia hegemônica, uma ideologia já imposta pelo Estado e pela sua classe dominante, a burguesia; a Barbarói, Santa Cruz do Sul, n.53, p.<89-116>, jan./jun. 2019 
segunda forneceria à escola uma autonomia relativa para expandir as estratégias de comunicação da ideologia dominante. A escola seria o principal aparelho ideológico do Estado, porque é o único que dispõe de tempo para sistematicamente agir sobre o indivíduo. Ela também guarda a responsabilidade pela produção e reprodução da força de trabalho.

Para Baudelot e Establet (1975), duas tramas de escolarização permaneceriam nos sistemas de ensino da França. Por um lado, a rede "secundária-superior" estaria dedicada às pessoas das classes privilegiadas. Delas sairiam os trabalhadores bastante intelectualizados. Sua escolaridade seria longa e o "sucesso escolar" estaria seguro. No lado oposto, a rede "primária-profissional" atendia aos filhos do proletariado, produzindo o trabalhador manual, em que a escolaridade seria sintetizada e a doutrinação auferida para o servilismo à classe dominante. As divisões escolares obedeceriam a um currículo inteiramente baseado no código dominante, que beneficia àqueles capacitados desde a socialização familiar. As instituições oficiais de ensino penalizariam os que não estivessem preparados, evidenciando seus problemas e suas dificuldades de aprendizagem.

Em Bowles e Gintis (1974), a composição das relações vivenciadas no ambiente escolar orientaria as altercações de resultados acadêmicos entre classes sociais. A função escolar não pretenderia somente qualificar a mão-de-obra técnica ou especializada; ela socializaria os jovens para o destino de um regime sistemático de trabalho hierarquizado. Não obstante, nesse olhar os sistemas de ensino determinam um caráter efetivo na "domesticação" dos indivíduos, na interiorização dos valores da economia do capital.

Não obstante, a obra de Pierre Bourdieu $(1992,2008)$ pode ser vista como dotada da maior capacidade de articular uma diversidade grande de fenômenos com um bom conjunto de recursos conceituais. A sociedade deve ser entendida a partir da noção de espaço social, um espaço de posições sociais e relações de poder em disputa e movimento. No espaço social, é possível caracterizar os diferentes campos, espécies de microcosmos relativamente autônomos, campos de disputa de posições sociais ocupados pelos agentes e seus diferentes capitais (econômico, cultural, social e simbólico).

O campo é como uma rede de relações objetivas propugnadas entre posições objetivamente delineadas através de uma relação objetiva com outras posições. Em se tratando das posições, elas são caudatárias da situação em que o campo se encontra e das suas potencialidades - no interior da estrutura do campo. Isso significa que o fato do agente ter ou não os capitais requisitados (ou os poderes equivalentes) pelo ritmo do campo comanda a conquista dos lucros a ele conferidos. Esses capitais se manifestam nos campos por meio do 
habitus, um sistema de disposições gerativas duráveis e transponíveis, estoques de respostas dos agentes para as situações do cotidiano.

Em Bourdieu, estaria no patamar cultural global dos núcleos familiares o eixo explicativo das relações de sucesso ou fracasso dos estudantes nas instituições educacionais. "Em todos os domínios da cultura, teatro, música, pintura, jazz, cinema, os conhecimentos dos estudantes são tão mais ricos e extensos quanto mais elevada é sua origem social" (BOURDIEU, 2007, p. 45). Para além do contato direto com bens culturais e do "treinamento familiar", os jovens das classes privilegiadas herdam saberes, gostos e disposições culturais que se encaixam nas demandas do ensino institucionalizado.

A escola privilegiaria os privilegiados, pois não leva em conta a disparidade cultural anterior à entrada dos alunos no seu “jogo". São aplicados métodos semelhantes, avaliações semelhantes e pedagogias semelhantes para pessoas portadoras de habitus de classe bastante desiguais, principalmente no que tange ao capital cultural. "É, enfim, a lógica própria de um sistema que tem por função objetiva conservar os valores que fundamentam a ordem social" (BOURDIEU, 2007, p. 56).

Para Bourdieu (2010, 1996), do habitus decorre a incorporação do capital cultural por parte dos estudantes. Aí está a engrenagem que distingue os grupos sociais de origens desiguais no interior dos estabelecimentos de ensino formal. O habitus é a maneira como as estruturas sociais se imprimem na racionalidade e no corpo dos agentes, por meio da interiorização da exterioridade, estruturas estruturadas que agem como estruturas estruturantes. Quando no campo escolar, esses jovens cujos passados incorporados, cujas disposições colidem com os regramentos do jogo acadêmico, veem-se fora de contexto e negligenciados pelos sistemas de ensino. Assim, seriam reproduzidas as relações de desigualdades sociais que antecedem a escolarização, o que acabaria mantendo as diferenças de origem social durante a ingerência escolar nas vidas dos educandos.

Desigualdades de oportunidades e estratificação educacional

Ambicionando superar tanto as teorias funcionalistas quanto as teorias reprodutivistas, muitos autores têm investido seus esforços de pesquisa nas complexidades da estratificação educacional, recorrendo a uma gama ampliada de países e casos. Com frequência, tem-se atentado para as relações entre a expansão dos sistemas de ensino e as desigualdades de oportunidades educacionais, e tem-se apresentado uma miríade de relações que vão além do que as demais teorias haviam conseguido explicar (MONT'ALVÃO, 2011).

O modelo de mobilidade educacional presente nos estudos de Spady (1967) procura entender as probabilidades de os estudantes finalizarem as transições escolares nos Estados Barbarói, Santa Cruz do Sul, n.53, p.<89-116>, jan./jun. 2019 
Unidos. O sistema escolar foi pensado como um mecanismo de seleção encarregado de separar e eliminar os discentes com menores oportunidades, motivações e habilidades requeridas pelos processos de educação formal. Analisando diferentes momentos do desenvolvimento escolar, mirando os percalços vividos pelas crianças das classes populares nas transições internas aos estabelecimentos de ensino, foram mensuradas as probabilidades de cada uma das transições. Seus resultados indicaram que as chances de concretizar as transições cresceram para todos os grupos sociais e no desenrolar das coortes, ainda que, para chegar ao ensino superior, as desvantagens das famílias com condições sociais mais vulneráveis se acentuaram na comparação com as famílias das classes mais altas.

Noutro achado, notou-se que a influência da educação do pai sobre as possibilidades dos discentes começarem e terminarem o ensino básico caiu ao longo das coortes. Em praticamente todos os níveis de transição, contudo, o efeito da cor da pele esteve evidente, sendo os brancos impingidos de maiores chances de alcance educacional, do início ao fim das trajetórias escolares. Spady (1967) verificou, portanto, que a ideia de que a educação formal nas sociedades modernas, se incentivada a sua qualidade, poderia acarretar como consequência direta a superação das barreiras da origem social dos discentes não se confirmou por completo. Educação e treinamento de maior qualidade poderiam, inclusive, fazer crescer o efeito do background familiar nas diferenciações entre os grupos sociais, à medida que os educandos mantivessem algumas vantagens específicas provenientes das suas vivências anteriores. Essas vantagens favoreceriam a probabilidade de seguir ou mesmo aumentar os seus níveis de status na comparação com os estudantes das classes populares.

Mare (1981, 1980) elaborou o "Modelo de Seletividade Diferencial”, a partir de regressões logísticas que mensuraram a probabilidade do discente realizar certas transições no desenvolvimento escolar, considerando a trajetória dos impactos das origens sociais durante as coortes. A abordagem indicou o impacto diferenciado das características familiares em cada transição, para o caso dos Estados Unidos. Fez-se, então, uma das afirmações que geraram um lastro de pesquisas: o impacto das origens sociais tende a diminuir no decorrer das trajetórias estudantis, não obstante seus efeitos sejam fortes nas transições iniciais nos sistemas de ensino.

Haveria, em consonância com os trabalhos de Spady (1967), uma espécie de processo de seleção social no interior da escolarização, capaz de obstruir os discentes das classes populares nas suas ambições de finalizar as primeiras transições educacionais. Assim, somente os estudantes cuja dedicação fosse acima da média conseguiriam avançar até chegar às transições mais altas no sistema. Nas transições mais elevadas, apenas os educandos Barbarói, Santa Cruz do Sul, n.53, p.<89-116>, jan./jun. 2019 
desmotivados e pouco dedicados não obteriam condições de avançar, enquanto nas transições primárias a lógica seria inversa.

Nas pesquisas de Mare $(1981,1980)$, o fato relevante reside na assertiva de que as correlações entre os aspectos socioeconômicos das famílias dos estudantes e outras variáveis conexas e o sucesso na escolarização seria mais baixa quanto maior fosse a etapa de transição educacional. Isso indica que a origem social vai perdendo peso nas explicações sobre as carreiras escolares, sendo mediadas através de elementos nem sempre mensurados, como a dedicação e a motivação individual. O padrão de constância dos efeitos das origens sociais ao longo das coortes, isto é, a evidência de que os impactos das condições sociais não seriam diferentes entre as pessoas das coortes mais e menos jovens no interior das transições, pode ser entendido como uma negativa das proposições das teorias funcionalistas (MONT’ALVÃO, 2011).

Shavit e Blossfeld (1993) organizaram um vasto material de investigação acerca da estratificação educacional em 13 nações, utilizando o "Modelo de Seletividade Diferencial" de Mare. Seus achados apresentaram a redução dos impactos das condições sociais das famílias perante as diferentes transições escolares, mas também a estabilidade dos efeitos das origens sociais entre as gerações. A ocorrência do crescimento da presença de discentes de todas as classes sociais em todos os âmbitos de ensino não retirou, necessariamente, os benefícios relacionados com o background familiar privilegiado em praticamente todos os países estudados. Em função de políticas específicas de emparelhamento de condições socioeconômicas, na Holanda e na Suécia foram vistas quedas das influências das origens sociais nos alcances educacionais, concretizando, assim, duas excepcionalidades.

A conclusão originada dos trabalhos organizados por Shavit e Blossfeld (1993) direciona para a validade do "Modelo de Seletividade Diferencial" engendrado por Mare. Os autores extrapolaram essa validade e propuseram uma espécie de padrão geral de compreensão da estratificação educacional nas sociedades modernas, compostas pela noção de que os sistemas de ensino iriam, aos poucos, abrindo as oportunidades para que os estudantes das classes populares driblassem os empecilhos enfrentados previamente. Significa que as distintas gerações iriam progredindo devagar nas hierarquias educacionais e os efeitos das origens sociais diminuindo das primeiras para as demais transições. Entretanto, destaca-se que esse movimento é freado quando se trata da educação superior. Nesse nível, os grupos sociais privilegiados deparar-se-iam com maiores probabilidades de seguir adiante e manter as suas posições. 
Os "Modelos de Seletividade Diferencial" também foram aplicados para o caso do Brasil. Silva, Mello e Souza e Roditi (1985) se debruçaram sobre as tendências através do tempo na estratificação educacional brasileira. Foi possível perceber uma estabilidade temporal contundente no que concerne ao impacto das origens sociais no alcance educacional. A principal variável expressando a relação esteve associada à educação do pai, no desenrolar das coortes de 1912 e 1956. Com base nisso, asseverou-se que a sociedade brasileira prosseguiu com uma estrutura de estratificação social quase inalterada num período de quase quatro décadas. Se nesse mesmo espaço de tempo o Brasil passou por um atestado processo de modernização e industrialização, as teorias funcionalistas receberam mais um golpe a partir dos referidos achados (MONT’ALVÃO, 2011).

Tendo como material empírico os dados da Pesquisa Nacional por Amostra de Domicílio (PNAD) de 1981, 1990 e 1999, Silva (2003) pensou o desenvolvimento da expansão educacional ocorrido no Brasil. Demostrou que a transição para a $1^{\mathrm{a}}$ série do ensino fundamental alcança quase a totalidade dos estudantes e que o impacto das variáveis que operacionalizaram a origem social dos discentes possui uma tendência decrescente no conjunto das transições. Contudo, a variável que indica a renda e a variável que indica a cor da pele não corroboraram essa tendência, mas, sim, cresce o seu efeito ao longo das transições escolares. As evidências apontadas pelo autor exibem o deslocamento da seletividade econômica e referente à cor da pele aos âmbitos mais elevados das etapas escolares. Sob o prisma da evolução no tempo, as evidências denotaram uma estabilidade no impacto da renda e uma queda parcial e lenta no impacto da cor da pele com o passar dos anos.

Sustentada pela base de dados da PNAD 1988, Fernandes (2005) analisou a influência nas transições escolares das variáveis que ilustram a origem socioeconômica, a cor da pele e a residência em área urbana por parte das famílias dos educandos. Fez-se plausível argumentar que houve uma diminuição do impacto da educação dos entes familiares no desenrolar das coortes, assim como com relação à variável de gênero. Por outro lado, a influência da cor da pele e da residência em área urbana demonstrou um viés oposto, à medida tais variáveis tendem a aumentar o seu impacto conforme ocorrem as transições. O efeito da origem social, com o foco nos elementos socioeconômicos, descortinou-se robusto nas primeiras etapas escolares, enfraquecendo nas etapas posteriores. A autora alegou que essa relação assinala que os discentes que chegam aos degraus superiores na escolarização parecem mais homogêneos e se sujeitam menos às vinculações de sua origem social do que, por exemplo, às suas habilidades e motivações particulares. Porém, quando entra em cena o efeito da cor da pele, a expansão dos sistemas educacionais não conseguiu atenuar as diferenças entre brancos e não Barbarói, Santa Cruz do Sul, n.53, p.<89-116>, jan./jun. 2019 
brancos. Quanto à validade ou não do "Modelo de Seletividade Diferencial" de Mare, Fernandes defende que é possível concordar apenas em parte, visto que não dá conta de explicar a relevância da cor da pele no contexto brasileiro.

Há ainda a investigação de Torche (2010), embasada nos dados da Pesquisa de Padrões de Vida, datada de 1996 e 1997. Seus achados induzem à ideia de que houve um crescimento das desigualdades de oportunidades educacionais na probabilidade de se completar o ensino médio e adentrar ao âmbito universitário, não só no Brasil como na América Latina. Também disserta sobre o desenvolvimento da expansão educacional no Brasil, comparando-o com países como a Rússia, sobretudo pelo fato de que a volumosa expansão da educação básica não foi acompanhada na mesma proporção pelo ensino superior. Dessa maneira, a competição se acentuou na tentativa de conquistar um espaço na educação superior, local ainda privilegiado, a despeito do alcance de todas as classes sociais ao ensino básico (MONT’ALVÃO, 2011).

Muller e Karle (1993) pesquisaram sobre as desigualdades de oportunidades educacionais numa série de países europeus. Em geral, a chamada "Abordagem do Curso de Vida" constata um padrão semelhante aos demais estudos a respeito das transições escolares, com os impactos das origens sociais intensos nas primeiras transições e perdendo força com o passar das demais transições no ensino básico. O ponto a se sublinhar no trabalho de Muller e Karle repousa na sua proposta explicativa sobre a diminuição do impacto das condições sociais nas carreiras acadêmicas. Os autores creditam esse movimento não à maior seletividade social nas primeiras transições educacionais, e, sim, às transformações no curso das relações entre estudantes e seus familiares. Asseveram que no transcorrer das etapas escolares os estudantes crescem e podem estabelecer uma relação de menor dependência aos pais, em se tratando dos fatores socioeconômicos. Isso explicaria a tendência de queda ao longo das transições escolares.

Raftery e Hout (1993) buscaram o modelo de análise da seletividade diferencial e a Teoria da Escolha Racional para elaborar a "Hipótese da Desigualdade Maximamente Mantida" (maximally maintained inequality). Explorando como objeto empírico as consequências da expansão do sistema educacional na Irlanda, essa teoria estipula que a redução da desigualdade de acesso a uma determinada etapa da trajetória escolar só aconteceria se o acesso à referida etapa estivesse saturado, do ponto de vista das classes sociais com maiores recursos. Nesse ritmo, a competição pela entrada na etapa em questão transfere-se para as etapas subsequentes da hierarquia das instituições escolares. 
Os desdobramentos da "Teoria da Desigualdade Maximamente Mantida" atingem a tese de que a expansão do sistema educacional formal seria acompanhada pela queda das desigualdades sociais. Pelo contrário, dando um passo atrás, as desigualdades de oportunidades educacionais se exibem estabilizadas ou, inclusive, em viés de crescimento. Os grupos sociais ocupantes de posições favorecidas tenderiam a se entrosar melhor com as posições oriundas da consolidação da expansão das redes de ensino. Os índices de transição e as razões de chance entre as variáveis que operacionalizam as origens sociais e as transições educacionais seguem similares para uma coorte após a outra. Os autores asseguram que somente quando os grupos com maiores privilégios estiverem próximos de $100 \%$ das chances de acesso, a desigualdade poderia entrar na curva descendente. Raftery e Hout (1993) sustentam que a "Teoria da Desigualdade Maximamente Mantida" edifica-se enquanto um parâmetro sólido para investigações de estratificação educacional, oferecendo as possibilidades de captura das dinâmicas de expansão e diferenciação de um leque amplo de nações e sistemas de ensino.

Shavit e Blossfeld (1993) também discutiram a "Hipótese da Desigualdade Maximamente Mantida" na obra em que organizaram múltiplos trabalhos sobre a temática. Eles perceberam que a teoria faz sentido e explica bem uma série de países analisados, descontando as nações que diminuíram as suas desigualdades sociais antes de acontecer a saturação das classes altas no acesso ao ensino básico, como a Holanda e a Suécia - ou como os Estados Unidos, em que a saturação do acesso ao ensino básico não gerou uma queda das desigualdades como consequência. Dito isso, a hipótese não teria capacidade de atuar como um modelo universal explicativo para a diminuição dos impactos das origens sociais ao longo das carreiras escolares; não conseguiria predizer todas as formas que as desigualdades no alcance educacional podem manifestar.

Silva (2003) comenta acerca da possibilidade de aplicação da "Hipótese da Desigualdade Maximamente Mantida" nos estudos sobre a estratificação educacional brasileira. Entende-se que três tópicos ilustrariam uma possível saturação da educação básica nacional: (a) a diminuição do impacto das variáveis que operacionalizam as origens sociais no transcorrer das transições escolares; (b) a quase totalização do acesso à transição primária do ensino fundamental; e (c) o deslocamento da seletividade escolar para às etapas mais elevadas do sistema de ensino. O autor alerta, no entanto, para a necessidade de problematizar o crescimento do efeito da cor da pele nas transições educacionais mais altas, ainda que em queda no decorrer das coortes, assim como para as diferenças em queda entre a residência em 
localidades rurais ou urbanas. Essas evidências não permitiriam afirmar que a "Teoria da Desigualdade Maximamente Mantida” encaixa sem lacunas no contexto brasileiro.

Outros trabalhos indicaram que o modelo logístico de análise das transições educacionais carrega uma restrição importante, ao considerar que os discentes avançam nas etapas escolares seguindo uma trajetória unilinear (LUCAS, 2001; BREEN \& JONSSON, 2000). Duas teses quase paradigmáticas, o "Modelo de Seletividade Diferencial" de Mare (1981, 1980) e a "Hipótese da Desigualdade Maximamente Mantida" de Raftery e Hout (1993) não possuem ferramentas para apreender os elementos qualitativos dos processos de estratificação educacional relacionados à expansão dos sistemas de ensino. Dependendo do país, as trajetórias educacionais podem experimentar caminhos alternativos (trackings), e os estudantes se diferenciar em função tanto das suas origens sociais quanto dos seus empenhos individuais. Podem incorrer distintas probabilidades de trajetórias nas sucessivas transições escolares. De acordo com Breen e Jonsson (2000), não captar os aspectos qualitativos representa subestimar os impactos das origens sociais nas transições primeiras e superestimar esse impacto nas transições mais elevadas, principalmente para o ensino superior. Eles apontam que também há um problema de heterogeneidade não mensurada, e que isso configuraria uma compreensão mais acurada para a diminuição dos efeitos das condições sociais no avançar das etapas escolares.

Breen e Jonsson (2000) construíram modelos logísticos multinomiais para investigar as desigualdades de oportunidades educacionais na Suécia. Usaram as notas dos estudantes como controle, a fim de minimizar os impactos de seleção originados das maiores capacidades cognitivas. Dessa maneira, verificaram que diferentes tracks escolhidos têm como consequência diferentes probabilidades de completar avanços nas transições escolares. Quanto à educação superior, a variável que mais se correlacionou com altas probabilidades de alcançar essa etapa foi a educação dos pais, condicionando os estudantes em desvantagem a procurar escolas mais qualificadas ou investirem nos seus próprios desempenhos para chegar a completar essa transição.

A bordo dessa linha de alegação, Lucas (2001) apresentou a "Hipótese da Desigualdade Efetivamente Mantida". A tese consiste em definir que os atores dotados de condições socioeconômicas mais elevadas certificam-se que eles e suas famílias não perderão quaisquer benefícios possíveis, qualitativos ou quantitativos. Se a "Hipótese da Desigualdade Maximamente Mantida" propõe que numa etapa educacional universalizada a competição pelo acesso seria nula, a tese da "Desigualdade Efetivamente Mantida" estipula que ainda em contextos de escolarização universalizada a competição prosseguiria. As disputas se dariam Barbarói, Santa Cruz do Sul, n.53, p.<89-116>, jan./jun. 2019 
por fatores como o tipo da escola, as referências de qualidade e etc. Quando certa etapa educacional estivesse saturada, não admitindo que a competição se transferisse para uma etapa superior, as desigualdades de acesso mudariam de estirpe e implicariam em disputas pelos caminhos mais prestigiados e seletos.

Numa incursão ao sistema de ensino estadunidense, cuja expansão se deu nos moldes da diferenciação de tracks (acadêmico e vocacional), Lucas (2001) pretendeu confirmar a validade dos seus argumentos. Indicou que os estudantes que provêm das classes altas demonstram maiores probabilidades de alcançar o track acadêmico, mais prestigiado, mesmo que não passem de regulares nas suas habilidades, na comparação com os discentes das classes populares, mesmo sendo mais dedicados. Os discentes oriundos das classes populares possuem maiores chances de se direcionarem para as community college, consideradas de menor prestígio. Nos Estados Unidos, essa é a via aparentemente mais sedutora para os indivíduos provenientes das famílias menos favorecidas em recursos, proporcionando elementos educacionais básicos que auxiliam a inserção no mercado de trabalho. De certo, um mercado de trabalho que contempla as ocupações também de menor prestígio social.

No que compete à desigualdade de oportunidades educacionais, a educação dos pais e a renda familiar, em paralelo ao número de irmãos, parecem ter maior relevância associada à transição à educação superior do que para finalizar o ensino básico. Lucas (2001) afirmou que estes resultados dificultam as coisas para a "Abordagem do Curso de Vida", minando os seus pressupostos. Contudo, em relação à "Hipótese da Desigualdade Maximamente Mantida", corrobora a premissa de que há um deslocamento da seletividade social na estratificação educacional para as etapas superiores das transições escolares, ao passo que as mais baixas tendem a saturar. Não foi um reflexo da expansão da educação básica e superior a queda das desigualdades de oportunidades educacionais e não se verificou o término da competitividade nas transições, como diria a "Hipótese das Desigualdades Maximamente Mantidas". O que houve foi o estabelecimento da evidência de que a educação básica figura enquanto um espaço competitivo, no qual a origem social tem efeitos incontestes nas trajetórias estudantis.

Outros que erigiram modelos multinomiais, no intuito de investigar a estratificação educacional, nesse caso em Israel, foram Ayalon e Shavit (2004). Suas pesquisas trouxeram indicativos de que os processos seletivos dos tracks acadêmicos correlacionam-se com as etnias e a classe social, beneficiando os judeus de origem europeia e os indivíduos das classes mais abastadas. Precedendo a saturação do acesso às etapas, a incidência dos impactos das origens sociais decai no decorrer das coortes. As universidades mais prestigiadas estariam, entretanto e de certa forma, garantidas para os grupos étnicos dominantes. Expandir Barbarói, Santa Cruz do Sul, n.53, p.<89-116>,jan./jun. 2019 
diferenciando o acesso formula circunstâncias nas quais a educação se faz mais disponível, mas traz consigo a retenção dos caminhos aos tracks acadêmicos por parte dos grupos sociais portadores de maior quantidade de recursos. Isso acabaria influenciando também a remuneração posterior no mercado de trabalho. Ocorreria, não obstante, a inclusão das classes populares na escolarização média sem importunar a reprodução dos interesses daqueles em vantagem na estratificação educacional.

Não somente o desenvolvimento da educação básica pode ser interpelado pelas perspectivas supracitadas. Nos Estados Unidos, uma gama variada de pesquisas ilustrou o aumento do número de matrículas de grupos étnicos não brancos, superior ao aumento de matrículas das pessoas brancas no ensino superior. Só que essas populações acabariam ocupando, em sua maioria, programas educacionais de no máximo dois anos de duração ou mesmo as community colleges, deixando para as universidades mais qualificadas os estudantes brancos (KAREN, 2002).

Baseado em informações sobre a estratificação educacional nas 25 nações integrantes do International Social Survey Programme (ISSP), datado de 1999, Hout (2006) traçou paralelos comparativos na intenção de testar a acurácia das teorias da "Desigualdade Maximamente Mantida" e da "Desigualdade Efetivamente Mantida". O autor associa a validade da "Hipótese da Desigualdade Maximamente Mantida" principalmente com as economias de mercado. Nessas economias, o impacto das variáveis que operacionalizam a origem social decresce quando ocorre a saturação dos estágios básicos de educação. Acerca das nações que outrora compuseram o bloco de Repúblicas Socialistas, Hout (2006) afirma que a hipótese que mais se encaixa é a das "Desigualdades Efetivamente Mantidas".

Silva e Mello e Souza (1986) procuraram entender, com originalidade, as relações entre as características das famílias e o desenvolvimento das carreiras escolares no Brasil, pensando a partir do modelo de transições escolares elaborado por Mare (1980). Eles se dedicaram a testar a hipótese de que, com a continuidade nas transições escolares por parte dos estudantes, a importância das origens sociais nas suas trajetórias de sucesso ou fracasso diminuiria. Foram utilizados os dados da PNAD de 1976, que proporcionou o enfoque sobre a trajetória educacional de indivíduos entre 20 e 64 anos. As principais variáveis que operacionalizavam a origem social remetiam a educação e ocupação do pai, ao lugar de nascimento, ao fato de ter nascido na cidade em que se encontrava no momento da pesquisa e a cor da pele. Às análises dessas características soma-se a construção de oito transições escolares. Seus achados esclareceram que os coeficientes das variáveis que indicam as origens 
sociais perdem força ao longo das transições. A única variável que contradiz esse resultado consiste naquela que indica o status ocupacional do pai do estudante.

Perseguindo as relações entre a industrialização brasileira e a estratificação educacional, Fernandes (2001) estudou o impacto das origens sociais sobre quatro transições escolares, centralizando na questão da cor da pele do estudante. O uso dos dados da PNAD de 1988 subsidiou as análises. A autora selecionou uma amostra com indivíduos a partir de 25 anos de idade. Nos modelos das transições escolares, foram usadas as variáveis que indicam a educação do pai e seu status ocupacional para operacionalizar as origens sociais dos discentes. Fernandes demonstrou que grande parte dos efeitos do background familiar obteve um padrão de declínio da mais baixa para a mais alta transição escolar. Foram exceções as variáveis de gênero e cor da pele. Abriu-se, assim, um espaço para o argumento de que a industrialização pode ter auxiliado na diminuição das desigualdades de oportunidades, através do impacto da educação e status educacional do pai e da evidência de sua tendência declinante. Entretanto, do ponto de vista de uma análise mais geral, a investigação elucidou uma estabilidade na desigualdade de oportunidades inter-coortes, quaisquer que fossem as medidas - socioeconômicas ou de cor da pele.

Os dados da PNAD de 1999 serviram de base para a investigação de Silva e Hasenbalg (2002), cuja ênfase esteve em mensurar o efeito das origens sociais sobre as trajetórias educacionais. Para operacionalizar as carreiras escolares, considerou-se desde a entrada do estudante no universo da escolarização até a finalização do ensino fundamental, por intermédio das características dos educandos de seis a 19 anos de idade. Os autores escolheram para indicar o background familiar as variáveis da renda do conjunto de pessoas constituintes, a educação daquele indivíduo considerado o chefe da família, a quantidade de filhos e agregados habitantes da mesa residência, a região em que o grupo familiar se localiza no país e a questão da residência urbana ou rural.

Como resultado, Silva e Hasenbalg (2002) trouxeram a perspectiva de que somente o impacto da educação do chefe familiar nas probabilidades de transição inter-séries caracteriza uma tendência decrescente, como prevê a teoria de Mare (1981), por exemplo. A localização regional, o local de residência e a vantagem das mulheres demonstram efeitos crescentes até a quarta série do ensino fundamental, declinando nas transições seguintes. Já a renda da família apresenta um impacto robusto na chegada ao sistema escolar, demonstrando queda até a quarta série. Os autores argumentam que o comportamento dos coeficientes possibilita indicar a supremacia dos indivíduos de pele branca em praticamente todo o trânsito na trajetória 
escolar, propiciando fortalecer a ideia de que o sistema de ensino tem dificuldades em combater ou mesmo atenuar as desigualdades raciais brasileiras.

Com o embasamento da série histórica envolvendo as PNAD’s de 1981, 1990 e 1999, Silva (2003) se propôs a avaliar as hipóteses de Raftery e Hout (1993), definidas na "Teoria da Desigualdade Mantida de Forma Máxima”. Por meio de uma amostra de pessoas entre seis e 19 anos de idade, foram estudados os efeitos das origens sociais sobre três transições escolares, quais sejam: a probabilidade de terminar a $1^{\mathrm{a}}$ série do ensino fundamental; a probabilidade de terminar a $4^{\mathrm{a}}$ série, considerando a conclusão da $1^{\mathrm{a}}$ série do ensino fundamental; e a probabilidade de terminar a $8^{\mathrm{a}}$ série, considerando a finalização da $4^{\mathrm{a}}$ série do ensino fundamental. A operacionalização da origem social tentou caracterizar o conceito de capital cultural, engendrado por Bourdieu (2010, 1996, 1992), com a indicação de uma variável sobre a educação do indivíduo tido como chefe da família. Na caracterização do capital econômico, foi indicada uma variável de renda da família. Houve também a caracterização da ideia de capital social, considerando a variável que determina se a chefe da família era mulher e qual o número de filhos na família.

As evidências mostraram um decréscimo na influência dos elementos que indicam a origem social dos estudantes sobre a primeira transição escolar, sobretudo na década de 1990. Porém, no que concerne às outras transições pesquisadas, os efeitos das origens sociais estiveram estabilizados na série temporal, demonstrados pela variável da educação do chefe familiar. Tais efeitos cresceram, inclusive, se observadas as variáveis pertinentes ao sexo do chefe familiar e a região de residência da família. No rastro dessas evidências, foi possível defender que somente um dos resultados corroborou a "Hipótese da Desigualdade Mantida de Forma Máxima", à medida que a diminuição dos impactos das origens sociais foi descrita como fruto da saturação nos primeiros degraus da trajetória educacional.

Rios-Neto, César e Riani (2002) prosseguiram os estudos sobre estratificação educacional no escopo do modelo de transições escolares inserido na abordagem de modelos hierárquicos. Eles estimaram o impacto das desigualdades de oportunidades educacionais operacionalizando as origens sociais com as variáveis da educação da mãe, o grupo e a posição na ocupação do pai. Usaram também variáveis indicando detalhes da oferta educacional na unidade da federação em que a residência da família estava vinculada, como o salário e a média de escolaridade dos docentes e uma proporção acerca da quantidade de professores do ensino fundamental e a população de sete a 14 anos de idade. Todas essas variáveis foram analisadas em suas relações com a probabilidade de término da $1^{\mathrm{a}}$ e da $5^{\mathrm{a}}$ séries do ensino fundamental.

Barbarói, Santa Cruz do Sul, n.53, p.<89-116>, jan./jun. 2019 
No trabalho em discussão, ganhou força a hipótese de Mare (1981), posto que, na esfera dos indivíduos, a influência das características sociais das famílias mostrou uma tendência mais forte na progressão para a $1^{\mathrm{a}}$ série do ensino fundamental do que nas demais avaliadas. Destaca-se a relevância dos resultados que remetem a percepção dos efeitos de substituição da educação da mãe pela escolaridade dos docentes na probabilidade de progressão na $1^{\mathrm{a}}$ série.

Riani e Rios-Neto (2008) continuaram as análises hierárquicas para os modelos de transições escolares, investigando as progressões no ensino fundamental e no ensino médio. Uma novidade do trabalho consistiu no uso da probabilidade do educando estar cursando a série certa na idade certa enquanto variável dependente. Seus achados apresentaram, outra vez, a relevância da educação da mãe no desenvolvimento escolar. Além disso, verificou-se a relevância também das variáveis contextuais que envolvem a qualidade da rede escolar na progressão dos discentes, e a diminuição da desigualdade de oportunidades educacionais oriunda do impacto da substituição da educação das mães dos estudantes.

Do ponto de vista das comparações com outros países, Costa Ribeiro (2009) argumenta que o Brasil não fica muito distante no sentido da evolução das desigualdades de oportunidades educacionais através do tempo, dado que não houve mudanças significativas entre as coortes analisadas. No entanto, a "Teoria da Desigualdade Persistente" (RAFTERY \& HOUT, 1993) parece não ser totalmente factível para a realidade brasileira, na medida em que não se mostrou a tendência declinante do efeito da educação materna e da ocupação paterna nas probabilidades de o estudante integralizar as transições escolares primárias. Somente nas transições mais avançadas é que a hipótese teórica da desigualdade persistente alcançou anuência nas evidências originadas do trabalho de Costa Ribeiro, com o crescimento do impacto da educação da mãe dos discentes na probabilidade de ingressar numa universidade.

A relação entre condições sociais e resultados na escolarização aparece nos trabalhos recentes de Duncan e Murnane (2011), ambos estadunidenses. Eles ressaltam que o aumento dramático do fosso entre as realizações educacionais das crianças que crescem em famílias ricas e pobres é uma realidade nos Estados Unidos. Entre 1978 e 2008, a diferença entre os resultados dos testes de leitura de crianças de famílias de alta e de baixa renda cresceu em um terço. Isso se reflete em um fosso crescente na escolaridade concluída. Nos últimos 20 anos, a taxa de crianças ricas que completou a faculdade aumentou 21 pontos percentuais, enquanto a taxa de graduação de crianças de famílias de baixa renda aumentou apenas quatro pontos percentuais (DUNCAN \& MURNANE, 2011).

Barbarói, Santa Cruz do Sul, n.53, p.<89-116>, jan./jun. 2019 


\section{Abrindo o esquema interpretativo: Sociologia da escola e abordagens diversas}

Vinte anos antes de acabar o século XX, ganhavam fôlego teorias e pesquisas em âmbito internacional que atacavam a visão de que a escola apenas reproduziria desigualdades, ou teria esse mote como seu eixo estruturador. Elas iniciaram uma época de outras percepções pertinentes à escolarização e suas possibilidades. Numa procura por conceituar os fenômenos adjacentes à escola de maneira mais ampla, eles começaram a ser vislumbrados no desenho de um espaço que pode tanto se sujeitar à manutenção do status quo, como proporcionar alterações sob os mais distintos aspectos.

O que se costumou chamar de "reprodutivismo" era percebido como um enfoque na inaptidão das instituições escolares em impulsionar a mobilidade entre classes. Nas novas visões de pesquisa, a escola representa um espaço sociocultural apto a colaborar para as mudanças sociais, econômicas, políticas e culturais. "A escola não é apenas conservadora ou transformadora, mas age simultaneamente no sentido da conservação e da transformação da estrutura social" (GLÓRIA, 2002, p.40).

Tadeu da Silva (1992) pensa a educação como uma "gangorra" entre inculcação e resistência, continuidade e descontinuidade, repetição e ruptura, manutenção e renovação. A educação formal se organiza para espalhar conhecimentos e saberes socialmente legitimados, cujo vínculo é estreito com a reprodução simbólica das classes dominantes. Compatível com isso, as instituições educacionais dilatam as relações de classe e possibilitam estratégias que podem favorecer as classes populares. A escola, ao mesmo tempo em que reproduz as desigualdades antecedentes a ela, compõe também um lugar para que as classes populares possam se apropriar do saber escolar e utilizá-lo em seu benefício.

É notável que a Sociologia tenha ampliado seus enfoques analíticos desde as últimas décadas. Pensar sociologicamente a instituição escolar tem sido uma trilha corriqueira nesse cenário amplificado de pesquisas, direcionado a superar o que pode ser definido como "determinismo" das teorias reprodutivistas. Diversos trabalhos têm o mérito de documentar a vida e a experiência escolar de mestres e aprendizes, de escolas ou de turmas de alunos. Principalmente nos Estados Unidos, multiplicam-se desde algum tempo os interesses por uma espécie de "Sociologia da Escola". "The Sociology of Teaching", livro reeditado por Waller em 1965, apoiado em métodos e conceitos derivados da Escola de Chicago, impetrados com vistas às coletividades urbanas, descreve e analisa a vida escolar, os rituais e as culturas escolares, o trabalho, as situações e o jogo dos estatutos e dos papeis (DEROUET, 1987, p. 87). 
Há também etnografias, como as de Hargreaves (1967), no Reino Unido, que investigam a vivência no ensino secundário institucionalizado. Halpin e Croft (1963), novamente nos Estados Unidos, cultivam as teorias ascendentes na Sociologia das Organizações e as derivam para o objeto escolar, compreendendo nestes locais as criações de lideranças. Ainda em meados dos anos 1980, outra linhagem com parentesco à anterior surgiu e tentou identificar os predicados e os estilos de gerenciamento que fariam eficientes e eficazes os colégios, com a prerrogativa de que as escolas "podem ter uma influência nas performances dos alunos, quaisquer que sejam as características sociais dos seus públicos" (DURU-BELLAT, 2002, p. 21).

No Brasil, os esforços de Maria Lígia de Oliveira Barbosa se concentram, mais recentemente, em analisar sob o prisma sociológico a instituição escolar. A autora aposta no desvendamento das relações sociais internas à escola, para estudar as razões ou, pelo menos, os fatores escolares que possam ser associados ao fortalecimento das desigualdades sociais (BARBOSA, 2009, p. 21). Através de investigações na região de Belo Horizonte, capital de Minas Gerais, analisando professores, alunos, funcionários e diretores de diferentes tipos de escolas, nota-se que existem diferenças de rendimento entre a qualidade das escolas e o sucesso ou fracasso dos estudantes em paridade de situações sociais.

Barbosa (2009, p. 31) descreve as técnicas usadas na pesquisa como "desenvolvidas mais recentemente para refinar e aprofundar a definição dos fatores escolares que influenciam diferencialmente os alunos". O raciocínio da autora percorre as diferenças raciais, de gênero e de classes sociais. Os surveys que sustentam os procedimentos metodológicos trazem informações acerca das características individuais e familiares dos estudantes, do funcionamento da sala de aula, dos métodos pedagógicos exercidos e das formas de organização da escola. Coexistem artifícios técnicos variados como a observação de aulas, dos cadernos mantidos pelos discentes, as entrevistas e os questionários. A mensuração dos desempenhos dos alunos origina-se das notas em português e matemática, por meio de avaliação ministrada pela Organização das Nações Unidas para a Educação, a Ciência e a Cultura (UNESCO). São estudantes avaliados de uma turma de $4^{\mathrm{a}}$ série sorteada em cada uma das escolas perfiladas no projeto.

A família como capital social se sobressai enquanto resultado empírico. As variáveis indicadoras dão conta de relações como a presença dos pais em casa, as diferenças de recursos sociais em famílias geridas por homens e mulheres, a ocupação materna, o tempo disponível da mãe, a ajuda recebida em casa e o número de filhos na família. Além disso, Barbosa (2009, 
p. 183) sintetiza "que o efeito da escola pode, pelo menos em parte, reduzir os efeitos da posição social dos alunos sob o seu desempenho escolar".

Já Laurens (1992) investiga os filhos de operários, com trajetórias desregulares que lhes alçaram ao ensino superior. Sair-se bem na escola tem uma justificação aliada às práticas educativas familiares de superinvestimento escolar. Há incorporada uma aguda decisão de superar as barreiras, criando um ambiente doméstico inclinado à escolarização. São variadas as configurações familiares possíveis, e elas oscilam entre a frequência a cursos pré-escolares, uma opção pelos estabelecimentos privados, a repartição de obrigações entre os entes e uma valiosa presença materna no acompanhamento das aprendizagens. Outros elementos relevantes são o associativismo religioso ou político das famílias e o fato delas possuírem menos membros.

As pesquisas de Terrail (1997) apontam casos de rendimentos satisfatórios e improváveis na escola. Há um elo interpretativo em que a escola tem sido intuída pelos pais como uma abertura para a mobilidade social, recaindo num apoio de investimento na educação, conjugado ao que os pais anseiam da institucionalidade. No caminho para direcionar um projeto escolar para os jovens, eles precisam enxergar as possibilidades de confrontar um longínquo período de percalços, “inscrevendo essa possibilidade numa representação global do social e de seu próprio lugar no social” (TERRAIL, 1997, p. 83).

Talvez esteja na obra de Bernard Lahire (1997) uma das abordagens mais interessantes simbolizando uma gama de estudos contemporâneos que investiga "histórias singulares" de alunos das classes populares com sucesso nas trajetórias escolares. Essas investigações objetivam compreender as trajetórias dos discentes na relação com as suas estratégias familiares. As famílias podem apadrinhar ou embaraçar a adequação dos filhos à vida acadêmica, podendo ter relação com a aprendizagem e os rendimentos escolares. A construção analítica de percursos escolares pode ser examinada através de pesquisadores como Nogueira (1991), Portes (1993), Lahire (1997), Viana (1998), Charlot (2000) e Zago (2000). Eles tratam do êxito ou não dos jovens nos seus universos de ensino, interpretando as relações que se fundam entre a herança cultural, as trajetórias e as estratégias educativas familiares de educandos das diversas classes sociais.

O trabalho de Lahire (1997) tem especial valor nesse ponto. Ele tentou entender como era cabível a existência de crianças que, em princípio, aparentavam elevada possibilidade de fracasso nas instituições educacionais, mas acabavam tendo bons resultados e até atingiam as melhores posições nas classificações escolares. No processo de pesquisa, foram entrevistadas 26 famílias, 27 crianças, docentes e diretores dos subúrbios de Lyon, na França. Lá a maior Barbarói, Santa Cruz do Sul, n.53, p.<89-116>, jan./jun. 2019 
parte dos moradores era composta por pais operários e mães donas de casa, além de se tratar de uma população com forte incidência estrangeira. $\mathrm{O}$ autor entende que a saída para analisar a posição "flutuante" da escolarização formal, que reproduz as desigualdades simbólicas de classe e, ao mesmo tempo, abre possibilidades de produção cultural, deve ser pensada nos seguintes termos, em oposição relativa ao que Bourdieu propunha com a noção de habitus:

\footnotetext{
Se considerarmos que os seres sociais se constituem - constroem suas estruturas mentais ou cognitivas - de forma contínua através das suas relações de interdependência, livramo-nos, então, da oposição entre ator e estrutura e, com isso, não é tão necessário dizer que "a ordem social se inscreve progressivamente nos cérebros" (LAHIRE, 1997, p. 353/354).
}

Para a pesquisa, Lahire (1997) escolheu estudantes localizados em famílias nas quais os "chefes" detinham baixo capital escolar, em conjugação com modestas condições financeiras. O estudo destaca que, mesmo com índices de capital cultural abaixo da expectativa, torna-se possível, através de relações dialogadas e da organização dos papéis domésticos, a construção de uma espécie de "lugar simbólico" para a escola e para o letramento, no coração das configurações familiares. Nessas ocorrências, prosperam situações que atribuem legitimidade à escolarização e conduzem, portanto, a desempenhos satisfatórios.

A noção de "disposições dos agentes", revelada por Lahire como alternativa ao habitus bourdieusiano, serve de cimento para a tese de que a presença objetiva de um capital cultural na família só tem significado se ele estiver em possibilidade de ser "transmitido". De fato, o determinante é se as pessoas responsáveis por socializar o agente possuem ou não as oportunidades e interesses para "transmitir" o capital cultural e, assim, fazer com que a cultura legítima se "torne corpo" nos jovens. Somente análises que desejem acompanhar configurações sociais específicas, contextualizadas, mostrar-se-iam capacitadas a oferecer subsídios concretos à Sociologia.

Lahire (1997) procura a compreensão de situações atípicas. Analisando o que chama de "configurações familiares", tenta perceber as dissonâncias e consonâncias entre elas e o mundo escolar no qual suas crianças estão inseridas. O autor pergunta e indica os caminhos a percorrer. Em que pese uma tendência a reificações em forma de conceitos, Lahire estipula como promissoras as análises das condições de existência e coexistência das pessoas. São as realidades intrínsecas aos seres sociais concretos que forjam os relacionamentos com as crianças e fazem com que elas tracem as suas relações com o mundo. O projeto do autor tem na reconstrução das redes de interdependências familiares pelas quais os estudantes elaboram seus arcabouços perceptivos, de julgamentos e avaliativos, o norte para a caracterização dos seus comportamentos escolares.

Barbarói, Santa Cruz do Sul, n.53, p.<89-116>, jan./jun. 2019 
Os conceitos de capital cultural familiar objetivado e capital cultural incorporado são analisados de modo a sublinhar aqueles casos em que as famílias adquirem livros e os disponibilizam aos filhos. No entanto, por não terem o capital cultural incorporado, poucos jovens tiram proveito deles. Incontáveis desses grupos sociais não governam com razoabilidade o tempo e o esforço para amparar os estudantes na edificação dos seus próprios capitais culturais. Em virtude disso, não basta que as famílias acumulem capital cultural e disposições culturais, se elas não são eficazes, por um motivo ou outro, na "transmissão" disso tudo para seus jovens membros. Mas o contrário também pode ocorrer. As famílias que quase nada carregam de capital cultural podem, doravante, executar uma intermediação entre a cultura escrita e os seus educandos. Facultam-se a isso quando pedem ou orientam seus filhos a ler e a escrever histórias, fazem perguntas sobre o que leram, vão à biblioteca municipal ou jogam palavras cruzadas com os filhos (LAHIRE, 1997).

\section{Considerações finais}

De modo sintético, neste artigo foi demonstrado que é preciso pensar a relação entre desigualdade e educação de distintas formas. É comum interpretar a educação formal como uma via aberta para a ascensão social, pela qual as pessoas que se dedicam aos estudos podem conquistar melhores postos de trabalho ou posições de maior destaque e reconhecimento na sociedade (DAVIS \& MOORE, 1979; PARSONS, 1970). Assim, num contexto de democracia política e economia de mercado, não seriam necessárias políticas públicas focadas diretamente no combate às desigualdades, por exemplo, porque o investimento em oportunidades educacionais de qualidade para todos, no longo prazo, traria consequências semelhantes com menos interferência governamental.

Há, contudo, a possibilidade de entender a educação formal sob a influência de outras lentes. Desde a década de 1960, especialmente desde a consolidação da Sociologia de Pierre Bourdieu (2008, 1996, 1992), as instituições educacionais passaram a ser vistas enquanto mecanismos de colaboração para a reprodução da estrutura de classes sociais, dada a sua atuação na manutenção dos privilégios presentes na sociedade. Considerando que tais estabelecimentos são organizados para trabalhar um determinado currículo, com determinadas ações pedagógicas e regras internas que seriam fruto de um arbitrário cultural dominante, os estudantes que possuem diferentes acessos aos bens e recursos culturais e diferentes disposições incorporadas para agir acabariam por se deparar com diferentes obstáculos durante as suas trajetórias acadêmicas. Ocorreria uma espécie de "exclusão opaca", travestida de democracia e diferença de méritos individuais, na medida em que se oferecem as vagas Barbarói, Santa Cruz do Sul, n.53, p.<89-116>, jan./jun. 2019 
para os jovens das diferentes classes, mas não se consegue automaticamente driblar todos os efeitos das desiguais origens sociais.

O exame crítico e empírico das teses bourdieusianas já foi realizado para o caso brasileiro. Recorrendo a abordagens quantitativas, analisei a influência do capital cultural no desempenho estudantil, com dados de 2003, operacionalizando o capital cultural através de uma escala de bens culturais e, depois, através de variáveis categóricas individuais que expressam escolaridade na família e hábitos culturais dos alunos (CAPRARA, 2016, 2013). Posteriormente, demonstrados os efeitos do capital cultural, investiguei e analisei, com dados mais recentes, os impactos da condição de classe dos discentes da educação básica sobre seus desempenhos em matemática e língua portuguesa (CAPRARA, 2017).

No entanto, restam muitas questões. Tudo indica que os trabalhos de Bernard Lahire oxigenam os estudos sobre as relações entre sociedade, educação e desigualdades, porque mergulham nas condições de emergência dos processos de socialização e na mediação entre as origens sociais e os contextos de atuação dos indivíduos. Ele está preocupado em desenvolver investigações sociológicas cujo foco recai sobre o "patrimônio disposicional" das pessoas, algo que vai muito além do "passado incorporado" presente no conceito bourdieusiano de habitus. A ideia é buscar a reconstrução da gênese das disposições, e para isso é preciso analisar a constituição social do passado dos agentes e as formas de atualização desse passado. Há aí uma virada na abordagem sociológica, pois Lahire $(2005,2003)$ propõe uma investigação à escala individual, para tentar compreender como as relações sociais se atualizam nas subjetividades e nos agregados individuais de disposições.

Essa perspectiva remete à interpretação dos fenômenos de individualização e diferenciação transcorridos nas sociedades modernas. Nessa linha, os indivíduos se veem em contato constante com “(...) processos multiformes de incorporação do social e se caracterizam por uma pluralidade interna de disposições heterogêneas, e até mesmo contraditórias" (ALVES, 2016, p. 311). A Sociologia focada ao individual pode informar acerca das complexidades disposicionais dos agentes, que demandam ser entendidos como situados em um determinado contexto social e frutos de socializações variadas. O indivíduo é percebido como resultado complexo de diferentes e múltiplos processos de socialização em situações contextuais heterogêneas. O singular não deixa jamais de ser plural (LAHIRE, 2005, p. 25).

A permanência dos efeitos das desigualdades sobre a educação formal não oblitera algumas indagações importantes. O que diferencia estabelecimentos escolares que conseguem "driblar" esses impactos? Como se dá a mediação entre as disposições e os contextos de Barbarói, Santa Cruz do Sul, n.53, p.<89-116>,jan./jun. 2019 
atuação dos agentes, para além de uma transferência mecânica entre origem e destino? Essas e outras perguntas podem incentivar os cientistas sociais a buscar entender a gênese e a atualização das disposições dos agentes e como esses agentes se relacionam com as interações próprias ao ambiente escolar. Esse pode ser um caminho bastante promissor para complementar as reflexões acerca das relações entre sociedade, educação e desigualdades no tempo presente.

\title{
SOCIETY, EDUCATION AND INEQUALITY: AN OVERVIEW OF THEORIES AND RESEARCH
}

\begin{abstract}
The article discusses the relations between society, education and social inequalities. The objective of the text is to map the contributions on the theme, focusing on different approaches, starting from the functionalism, through the reproduction theories, the educational stratification and the sociology of the school, until reaching the diversity of analyzes proposed from the decade of 1980. Rescues the contributions of these theories and research, introductory, considering their advances and setbacks, their scope and limitations. Thus, it organizes a synthetic overview about one of the most frequent relations in the debates about the educational phenomena of modernity.
\end{abstract}

Keywords: Society; Education; Inequalities.

\section{REFERÊNCIAS}

ALTHUSSER, Louis. Ideologia e Aparelhos Ideológicos do Estado: Notas Para uma Investigação. Lisboa: Editorial Presença, 1980.

ALVES, Ana. Dos habitus de classe aos patrimônios individuais de disposições: reflexões sobre a prática em Pierre Bourdieu e Bernard Lahire. Revista Sociologias, Porto Alegre, 2016.

AYALON, Hanna; SHAVIT, Yossi. Educational Reforms and Inequalities in Israel: the MMI Hypothesis Revisited. Sociology of Education, vol. 77, 2004.

BARBOSA, Maria Ligia de Oliveira. Desigualdade e desempenho: uma introdução à Sociologia da escola brasileira. Belo Horizonte: Argumentum, 2009.

BAUDELOT, Christian; ESTABLET, Roger. La Escuela Capitalista en Francia. México: Siglo Veintiuno, 1975.

BERNSTEIN, B. Codes, modalities and the process of cultural reproduction: A model. Language and Society, n. 10, pp. 327-363, 1981.

BOURDIEU, Pierre. A Distinção: crítica social do julgamento. Porto Alegre: Zouk, 2008. A Reprodução. Rio de Janeiro: Francisco Alves, 1992. 
. Escritos de Educação. Petrópolis: Vozes, 2007.

. O Poder Simbólico. Rio de Janeiro: Bertrand Brasil, 2010.

. Razões Práticas: Sobre a teoria da ação. Campinas: Papirus, 1996.

BOWLES, Samuel; GINTIS, Herbert. Schooling in Capitalist America: Educational Reform and the Contradictions of Economic Life. Nova Iorque: Basic Books, 1974.

BREEN, Richard; JONSSON, Jan O. Analyzing Educational Careers: A Multinomial Transition Model. American Sociological Review, vol. 65, nº 5, 2000.

CAPRARA, Bernardo. The Impact of Cultural Capital on Secondary Student's Performance in Brazil. Universal Journal of Educational Research, v. 4, n. 11, 2016.

. Classes sociais e desempenho educacional no Brasil. Tese de Doutorado, Programa de Pós-Graduação em Sociologia da Universidade Federal do Rio Grande do Sul., 2017.

A influência do capital cultural no desempenho estudantil: reflexões a partir do Saeb 2003. Dissertação de Mestrado Acadêmico, PPGS UFRGS, Porto Alegre, 2013.

CHARLOT, Bernard. Da Relação com o Saber: Elementos para uma Teoria. Porto Alegre: Artes Médicas Sul, 2000.

COSTA RIBEIRO, Carlos. Desigualdade de Oportunidades no Brasil. Belo Horizonte: Ed. Argumentum, 2009.

DAVID, K.; MOORE, W. Alguns princípios de estratificação. In: VELHO, O.; PALMEIRA, M.; BERTELLI, A. (orgs.). Estrutura de classes e estratificação social. Rio de Janeiro: Zahar Editores, 1979.

DUNCAN, Greg; MURNANE, Richard. Whitter opportunity? Rising Inequality, Schools, and Children's Life Chances. New York: Russel Sage Foundation, 2011.

DEROUET, Jean-Louis. Une sociologie des établissements scolaires: des difficultés de construction d'un nouvel objet scientifique. Revue Française de Pédagogie, n. 78, pp. 86108, 1987.

DURU-BELLAT, Marie. Les Inégalités Sociales à l'École: Genèse et Mythes. Paris: PUF, 2002.

FERNANDES, Danielle. Race, Socioeconomic Development and the Education Stratification Process in Brazil. Research in Social Stratification and Mobility, vol. 22, 2005.

Raça, Origem Socioeconômica e Desigualdade Educacional no Brasil: Uma

Análise Longitudinal. Trabalho apresentado no XXV Encontro Anual da Anpocs, Caxambu, MG, 2001. 
FORQUIN, Jean Claude. Sociologia da Educação: Dez anos de pesquisa. Petrópolis, RJ: Vozes, 1995.

GLÓRIA. Dília Maria Andrade. A escola dos que Passam Sem Saber: A Prática da nãoretenção Escolar na Narrativa de Alunos e Familiares. Dissertação de Mestrado Acadêmico. Belo Horizonte: PUC-MG, 2002.

HALPIN, Andrew; CROFT, Don. The Organizational Climate of Schools. Chicago: Administration Center, 1963.

HARGREAVES, David. Social Relations in a Secondary School. London: Routledge \& Kegan Paul, 1967.

HOUT, Michael. Maximally Maintained Inequality and Essentially Maintained Inequality: Cross national Comparisons. Sociological Theory and Methods, vol. 21, nº 2, 2006.

KAREN, David. Changes in Access to Higher Education in the United States: 19801992. Sociology of Education, vol. 75, nº 3, 2002.

LAHIRE, B. Patrimônios individuais de disposições. Para uma Sociologia à escala individual. Sociologia, Problemas e Problemáticas, n. 49, 2005.

Ática, 1997.

. Sucesso Escolar nos Meios Populares: As Razões do Improvável. São Paulo:

2002.

. O homem plural: os determinantes da ação. Petrópolis, Rio de Janeiro, Vozes,

LAURENS, Jean-Paul. 1 sur 500: La Reussite Scolaire en Milieu Populaire. Toulouse: Presses Universitaires du Mirail, 1992.

LUCAS, Samuel R. Effectively Maintained Inequality: Education Transitions, Track Mobility and Social Background Effects. The American Journal of Sociology, vol. 106, nº 6, 2001.

MARE, Robert. Change and Stability in Educational Stratification. American Sociological Review, vol. 46, $\mathrm{n}^{\circ} 1,1981$.

. Social Background and School Continuation Decisions. Journal of the American Statistical Association, vol. 75, 1980.

MONT'ALVÃO, Arnaldo. Estratificação educacional no Brasil do século XXI. Revista Dados, volume 54, número 2, Rio de Janeiro, 2011.

MULLER, Walter; KARLE, Wolfgang. Social Selection in Educational Systems in Europe. European Sociological Review, vol. 9, nº 1, 1993.

NOGUEIRA, Maria Alice. Trajetórias Escolares, Estratégias Culturais e Classes Sociais: Notas em Vista da Construção do Objeto de Pesquisa. Teoria \& Educação, Porto Alegre, n. 3, p. 89-112, 1991. 
PARSONS, Talcott. Equality and Inequality in Modern Society, or Social Stratification Revised. In: LAUMANN, E. (ed.). Social Stratification: Research and Theory for the 1970s. Indianapolis: Bobbs-Merril, 1970.

PORTES, Écio Antônio. Trajetórias e Estratégias Escolares do Universitário das Camadas Populares. Dissertação de Mestrado. Faculdade de Educação da UFMG, 1993.

RAFTERY, Adrian E.; HOUT, Michael. Maximally Maintained Inequality: Expansion, Reform, and Opportunity in Irish Education, 1921-1975. Sociology of Education, vol. 66, $\mathrm{n}^{\circ}$ $1,1993$.

RIANI, J. de L. R.; RIOS-NETO, E. L. G. Background familiar versus perfil escolar do município: qual possui maior impacto no resultado educacional dos alunos brasileiros? Revista Brasileira de Estudos Populacionais, v. 25, n. 2, jul/dez 2008.

RIOS-NETO, E. L. G.; CÉSAR, C. C.; RIANI, J. de L. R. Estratificação educacional e progressão escolar por série no Brasil. Pesquisa e Planejamento Econômico, v. 32, n. 3, dez 2002.

SEABRA, Teresa. Desigualdades escolares e desigualdades sociais. Sociologia, n. 59, p.75106, jan. 2009.

SHAVIT, Yossi; BLOSSFELD, Hans Peter. Persistent Inequality: Changing Educational Attainmet in Thirteen Countries. Boulder: Westview, 1993.

SILVA, Nelson do Valle. Expansão Escolar e Estratificação Educacional no Brasil. In: SILVA, Nelson do Valle; HASENBALG, Carlos. Origens e Destinos: Desigualdades Sociais ao Longo do Ciclo de Vida. Rio de Janeiro: Topbooks, 2003.

SILVA, Nelson do Valle; HASENBALG, Carlos. Recursos familiares e transições educacionais. Cadernos de Saúde Pública, Rio de Janeiro, 2002.

SILVA, Nelson do Valle; MELLO E SOUZA, Alberto de. Um Modelo para a Análise da Estratificação Educacional no Brasil. Cadernos de Pesquisa, número 58, 1986.

SILVA, Nelson do Valle; MELLO E SOUZA, Alberto de; RODITI, Déborah. Industrialização e Desigualdades Educacionais no Brasil. Rio de Janeiro, Laboratório Nacional de Computação Científica, Relatório de Pesquisa e Desenvolvimento, 1985.

SPADY, William G. Educational Mobility and Access: Growth and Paradoxes. The American Journal of Sociology, vol. 73, nº 3, 1967.

TADEU DA SILVA, Tomaz. O que produz e o que reproduz em educação: ensaios de Sociologia da educação. Porto Alegre: Artes Médicas, 1992

TERRAIL, Jean-Pierre. La Sociologie Des Interactions Famille/École. Sociétés Contemporaines, $\mathrm{n}^{\circ}$ 25, pp. 67-83, 1997.

TORCHE, F. Economic Crisis and Inequality of Educational Opportunity in Latin America. Sociology of Education, vol. 83, ñ 2, 2010. 
TREIMAN, Donald J. Industrialization and Social Stratification. In: LAUANN, E. Social Stratification: Research and Theory for the 1970s. Indianapolis: Bobbs-Merrill, 1970.

VIANA, Maria José Braga. Longevidade Escolar em Famílias de Camadas Populares: Algumas Condições de Possibilidades. Tese de Doutorado. Belo Horizonte: FAE/UFMG, 1998.

ZAGO, Nadir. Processos de Escolarização nos Meios Populares: As Contradições da Obrigatoriedade Escolar. In: NOGUEIRA, M. A.; ROMANELLI, G.; ZAGO, N. (orgs.).

Família e Escola: Trajetórias de Escolarização em Camadas Médias e Populares. Petrópolis: Vozes, 2000. Páginas 17-43.

Data de recebimento: $18 / 06 / 2019$

Data de aceite: 17/09/2019

\section{Sobre o autor:}

Bernardo Caprara é Professor de Ciências Sociais na Universidade Federal da Fronteira Sul (UFFS), Doutor em Sociologia pela Universidade Federal do Rio Grande do Sul (UFRGS) e líder do Grupo de Pesquisas e Intervenções Sociedade, Educação e Desigualdades (SOCIEDUDES). Endereço Eletrônico: bernardocaprara@gmail.com. 